\title{
Making Sense of Racial Disparities in Gastrointestinal Cancer Mortality
}

\author{
Adeyinka O. Laiyemo
}

Received: 18 September 2012/ Accepted: 19 September 2012/Published online: 20 October 2012

(c) Springer Science+Business Media New York 2012

Studies have demonstrated that colorectal cancer incidence and mortality are higher among blacks in the United States as compared to other race-ethnicities [1-3]. However, there is limited information regarding racial differences in the burden of other gastrointestinal cancers. Evaluating the burden of gastrointestinal cancers among different race-ethnicities may enhance our understanding of the etiology of the disease processes and guide strategies to adopt in order to reduce the burden of these diseases among minority populations.

In this issue of the journal, Jinjuvadia et al. [4] used the third National Health and Nutrition Examination Survey (NHANES III) and related mortality data files to evaluate racial differences in mortality from gastrointestinal cancers. The authors reported a two-fold increased risk of death from gastrointestinal cancers among non-Hispanic blacks (blacks) when compared to non-Hispanic whites (whites). In particular, there were statistically significant increased mortalities from esophageal, pancreatic, and colorectal cancers among blacks. In exploratory analysis in which the authors evaluated racial differences by sex, they reported an increased mortality risk from gastric cancer, primary liver cancer, and colorectal cancer among black men as compared to white men. Overall, black women had a non-statistically significant increased mortality risk, but were significantly more likely to die from esophageal and pancreatic cancers when compared to white women. Interestingly, there was no cancer mortality that was higher among whites in any of the analysis presented in this study. However, this current analysis in a nationally representative data is limited by the

\footnotetext{
A. O. Laiyemo ( $\square)$

Division of Gastroenterology, Department of Medicine, Howard University College of Medicine, 2041 Georgia Avenue NW, Washington, DC 20060, USA

e-mail: adeyinka.laiyemo@Howard.edu
}

low absolute numbers of cancers diagnosed in the follow-up period, and lack of information on patients' comorbidities, stage of cancer diagnosis, and cancer treatments received. Nonetheless, it provided insight into disproportionately increased burden of gastrointestinal cancers among blacks.

Making sense of the suggested disparities in this study requires a detailed analysis of the potential explanations for the findings. There are three major issues that may be involved in the different risks of death from these cancers:

a) Higher prevalence of predisposing risk factors: A higher prevalence of putative risk factors that have been shown to increase the risk of particular cancers will be associated with a disproportionately higher risk of developing the disease. For instance, infections with viral hepatitis $B$ and hepatitis $C$ have been associated with increased risk of hepatocellular carcinoma while Helicobacter pylori infection has been associated with increased risk of gastric cancer. Behavioral and lifestyle choices that have been identified as increasing the risk of gastrointestinal cancers include: obesity with colorectal cancer [5, 6], smoking with pancreatic cancer [7], and alcohol ingestion with esophageal, pancreatic, and colorectal cancers $[8,9]$.

b) Lack of uptake of preventive care services: Although few cancers have been shown to be amenable to screening, disparities in utilization of screening services and early detection can lead to late-stage presentation of cancers with limited options for cure.

c) Differences in the quality of treatment following cancer diagnosis: Delay in care or provision of substandard care may lead to differences in cancer mortality rates. This may result from lack of healthcare access (care providers and facilities) and lower utilization of healthcare resources. 
It is well known that blacks tend to have poorer access to healthcare services and are also less likely to utilize their healthcare benefits, which may lead to late-stage presentation when cure is less likely to be achieved [10-12]. However, the prevalence of behavioral and lifestyle risk factors for the diseases may also be higher among blacks which will make them more susceptible to the malignancies [13]. For instance, Jinjuvadia et al. [4] reported that esophageal cancer mortality was higher among blacks. The risk factors for esophageal cancer include alcohol consumption and cigarette smoking, both of which are common among blacks [13]. It is well known that cigarette smoking is a putative risk factor for pancreatic cancer as well [7]. Racial disparity in the burden of colorectal cancer has been more extensively studied. It is the only gastrointestinal cancer that has been shown to be amenable to screening in randomized control trials [14, 15]. However, blacks are less likely to be screened $[10,11]$ or to have optimal diagnostic follow-up after an abnormal screening [16]. Studies have also suggested that blacks tend to receive substandard cancer care when compared to whites [17] with reduction and elimination of black-white differences in survival when equitable treatment was received by patients regardless of race-ethnicities [18, 19]. The observed lower access and utilization of healthcare resources may contribute to the increased cancer-related mortality among blacks.

Although not a focus of the current study by Jinjuvadial et al. [4], there may also be a complex interplay of environmental and biological (including genetic) susceptibilities to cancer that may affect the burden of specific cancers among minorities. It is well known that Asians have a higher burden of gastric cancer in the United States, which may be related to the high prevalence of Helicobacter pylori infection. However, blacks also have a high prevalence of Helicobacter pylori infection but the burden of

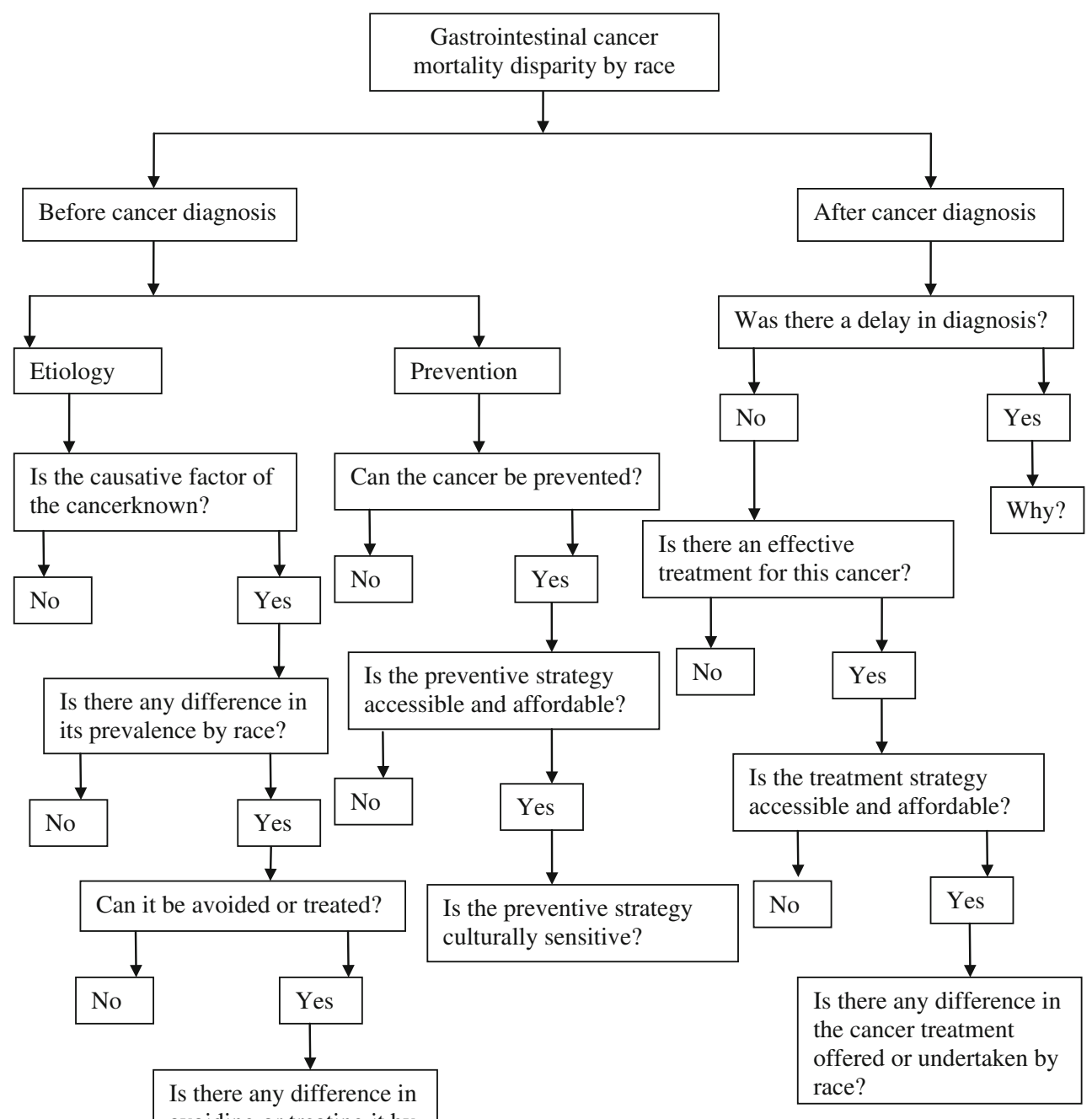

Fig. 1 A proposed algorithm for evaluating disparities in gastrointestinal cancer-related mortality 
gastric cancer is lower, underscoring the fact that more research is needed to further understand differences in susceptibility to diseases suffered by different groups.

Racial disparity in the burden of cancer is often complex and affected by the prevalence of etiological risk factors for the diseases, availability and uptake of screening and early detection services, as well as cancer patients' undergoing effective treatment modalities (Fig. 1). However, the solution to reduce disparities will begin with an understanding that the disparities exist, evaluating the causative factors for the disparities, increasing the pipeline of minorities as care providers while increasing the participation of minorities in clinical research as patients and investigators [20]. In recognition of the need to increase the pool of minorities as gastroenterologists, the American Gastroenterological Association (AGA) established the Diversity Program as part of the Investing in the Future programs. This effort was intended to encourage highly qualified minority internal medicine residents to choose the field of gastroenterology for their careers [http://www. gastro.org/corporate-relations/sponsorship-opportunities]. The American Society for Gastrointestinal Endoscopy (ASGE) also established the ASGE Diversity Awards in 2007. This provides a financial award of $\$ 1,000$ to the first authors of two proffered abstracts submitted for presentation at the annual Digestive Diseases Week (DDW) and focused on the underserved populations [http://www.asge. org/research/research.aspx?id=10458].

In summary, we need to better understand where disparities occur in the continuum of care of the population in order to better address the disproportionately higher incidence and mortality from gastrointestinal cancers among minorities.

\section{References}

1. Siegel R, Naishadham D, Jemal A. Cancer statistics, 2012. $C A$ Cancer J Clin. 2012;62:10-29. (PMID: 22237781).

2. Howlader N, Noone AM, Krapcho M, et al. SEER cancer statistics review, 1975-2009 (vintage 2009 populations), National Cancer Institute. Bethesda, MD, http://seer.cancer.gov/csr/ 1975_2009_pops09/, based on November 2011 SEER data submission, posted to the SEER web site, 2012. Accessed on May 25, 2012 at http://seer.cancer.gov/statfacts/html/colorect.html.

3. Chien C, Morimoto LM, Tom J, Li CI. Differences in colorectal carcinoma stage and survival by race and ethnicity. Cancer. 2005; 104:629-639.
4. Jinjuvadia R, Jinjuvadia K, Liangpunsakul S. Racial disparities in gastrointestinal cancers related mortality in the US population. Dig Dis Sci. 2012 (Epub ahead of print). doi:10.1007/s10620012-2312-3.

5. Giovannucci E, Ascherio A, Rimm EB, et al. Physical activity, obesity, and risk for colon cancer and adenoma in men. Ann Intern Med. 1995;122:327-334.

6. Renehan AG, Tyson M, Egger M, et al. Body-mass index and incidence of cancer: a systematic review and meta-analysis of prospective observational studies. Lancet. 2008;371:569-578.

7. Wittel UA, Momi N, Seifert G, Wiech T, Hopt UT, Batra SK. The pathobiological impact of cigarette smoke on pancreatic cancer development (review). Int J Oncol. 2012;41:5-14.

8. Pöschl G, Seitz HK. Alcohol and cancer. Alcohol Alcohol. 2004;39:155-165.

9. Haas SL, Ye W, Löhr JM. Alcohol consumption and digestive tract cancer. Curr Opin Clin Nutr Metab Care. 2012;15(5): 457-467.

10. Sharma S, O'Keefe SJ. Environmental influences on the high mortality from colorectal cancer in African Americans. Postgrad Med J. 2007;83:583-589.

11. Doubeni C, Laiyemo AO, Reed G, Field T, Fletcher R. Socioeconomic and racial patterns of colorectal cancer screening among Medicare enrollees 2000-2005. Cancer Epidemiol Biomarkers Prev. 2009;18:2170-2175.

12. Doubeni CA, Jambaulikar GD, Fouayzi H, et al. Neighborhood socioeconomic status and use of colonoscopy in an insured population-a retrospective cohort study. PLoS One. 2012;7: e36392.

13. Joshu CE, Parmigiani G, Colditz GA, Platz EA. Opportunities for the primary prevention of colorectal cancer in the United States. Cancer Prev Res (Phila). 2012;5:138-145.

14. Schoen RE, Pinsky PF, Weissfeld JL, et al. Colorectal-cancer incidence and mortality with screening flexible sigmoidoscopy. $N$ Engl J Med. 2012;366:2345-2357.

15. Atkin WS, Edwards R, Kralj-Hans I, et al. Once-only flexible sigmoidoscopy screening in prevention of colorectal cancer: a multicentre randomised controlled trial.Lancet. 2010;375:1624-1633.

16. Laiyemo AO, Doubeni C, Pinsky PF, et al. Race and colorectal cancer disparities: health-care utilization vs different cancer susceptibilities. J Natl Cancer Inst. 2010;102:538-546.

17. Steyerberg EW, Earle CC, Neville BA, Weeks JC. Racial differences in surgical evaluation, treatment, and outcome of locoregional esophageal cancer: a population-based analysis of elderly patients. J Clin Oncol. 2005;23:510-517.

18. McCollum AD, Catalano PJ, Haller DG, et al. Outcomes and toxicity in African Americans and Caucasian patients in a randomized adjuvant chemotherapy trial for colon cancer. $J$ Natl Cancer Inst. 2002;94:1160-1167.

19. Dominitz JA, Samsa GP, Landsman P, Provenzale D. Race, treatment, and survival among colorectal carcinoma patients in an equal-access medical system. Cancer. 1998;82:2312-2320.

20. Merchant JL, Omary MB. Underrepresentation of underrepresented minorities in academic medicine: the need to enhance the pipeline and the pipe. Gastroenterology. 2010;138:19-26.e1-3. 